\title{
Auditorium Acoustics From Past to Present
}

\author{
Kabiru Maishanu, Asst. Prof. Dr. Halil Zafer Alibaba \\ (Department of Architecture, Eastern Mediterranean University, Famagusta, TRNC) \\ (Department of Architecture, Eastern Mediterranean University, Famagusta, TRNC)
}

\begin{abstract}
The main aim of this paper is to identify how acoustics where generally achieve in auditoriums base on the method, technics and the materials been used. This paper will discuss the transition over time. It will cover how the design began from the past (Roman, Greek baroque, renaissance periods) to the present (twentieth century). The paper will further discuss some case studies which are from different periods. The selection of the case study was based on their excellent acoustics qualities of the spaces. It will provide better understanding on how acoustics solution where been achieve in auditoriums/theaters from the past to the present. Finally, the paper will point out some major benefits of using acoustics in auditoriums and also discuss on what causes poor quality sound in the present auditoriums and then suggest the use flat panels technology and line-stone material as it has great impact in in achieving good and qualitative acoustics in the past.

Keywords: Sound propagation, Reverberation time, Past theaters, $20^{\text {th }}$ century theaters, benefits of acoustics and loudspeaker system problem.
\end{abstract}

\section{INTRODUCTION}

Expressions of the human experience of music, show, and open talk have both affected and been impacted by the acoustics and design of their presentation surroundings. It is speculated that African music and move advanced a very unpredictable cadenced character instead of the melodic line of early European music due, to a limited extent, to its being performed outside. Wallace Clement sabine (1868-1919), an early pioneer in architectural acoustics, felt that the improvement of a tonal scale in Europe as opposed to Africa could be attributed to the distinctions in living environment. In Europe, ancient tribes looked for safe house in give in and later built progressively expansive and reverberant sanctuaries and temples. Gregorian serenade became out of the acoustical attributes of the Gothic houses of cathedrals, and consequently florid music was composed to suit the places of worship of the time. In the last $50 \%$ of the $20^{\text {th }}$ century, both theater design and performing expressions got to be innovation driven, especially with the development of the electronic frameworks that made film and TVs enterprises conceivable. With the improvement of PC projects link of making the look and sound of any environment, a showstopper can now impact, as well as characterize the space it possesses.

"Those of us in the $20^{\text {th }}$ century forget that generations before us had to congregate by the hundreds and thousands to hear the words of civilizations leaders and misleaders without the aid of sound engineers and public address systems. But the need to hear and see collectively was still there" (B. Cobbey criler, December 1976).
Auditorium, as a building for public gatherings (listing, speech or stage performance) is developed from classical open-air theaters. Its includes closed space meant for: concert, meeting, lecture halls and listing to music.

Design of auditorium became a complex problem to its various types, because in addition to that, sometimes conflicting, aesthetics, functional, technical, art istic and economical require ments.

The basic acoustical criteria of both the largest and smallest halls or rooms have no much different in some ways:

- Internal and external sources must have a low ambient noise level.

- Reasonable level of acoustic gain must be provided.

- Reverberation time provided must be appropriate.

- Artifacts such as echoes must be avoided.

Architectural considerations affect the conditions of hearing in auditorium. They include: sharp, site location, volume, seating arrangement, audience capacity, treatment of acoustic from interior to surface.

Defects: echo, delayed reflection, sound shadow and sound concentration.

\section{SOUND PROPAGATION IN AUDITORIUM}

Sound wave travel at about $345 \mathrm{~m} / \mathrm{s}$, which at about 0.01 to 0.2 seconds, the sound that came directly from the source within the auditorium will reach the listener.

The early reflection will occur after at about 50 milliseconds. The reflection that occurs 
after the early one are of lower amplitude which marge into the reverberant sound or late reflection. Reverberant sound builds up to an equilibrium level when source emit a continuous sound. The level of the sound decreases at more or less constant rate until it reaches inaudibility.

The reverberation sound begins to decay immed iately for impulsive sounds.

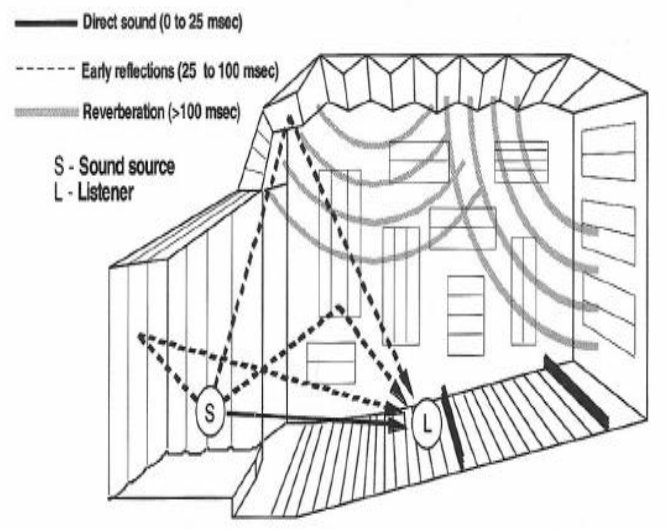

Fig 1: Direct, early reflections and reverberation of sound in an auditorium.

(Chris Foreman, Jul 6, 2015)

\subsection{Direct Sound or Early Reflection}

Direct sound will decrease by $6 \mathrm{~dB}$ for each doubling of distance propagated. Reflection which arrive within about 35 milli-second are not heard as separate from direct sound.

The source is perceived to be in the direction from which the first sound arrives provided that:

- Successive sound arrives within about 35 milliseconds.

- Successive sounds have spectra and time envelopes reasonable similar to the first sound

- Successive sounds are not too much louder than the first.

All of this are referred to as the precedence effect.

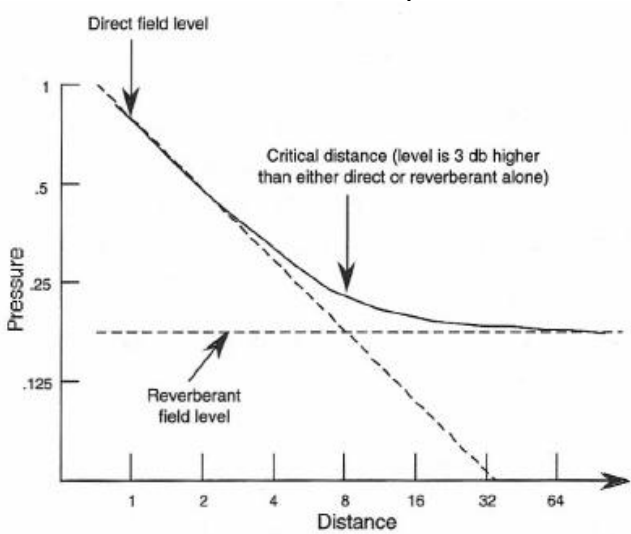

Fig 2: Relation between direct sound field and reverberant sound field in a room. (Chris Fore man, Jul 6, 2015)

\subsection{Late Reflection}

During a continuous sound, the reverberant level is reach when the rate at which energy is supplied by the source is equal to the rate at which sound is absorbed. Too much reverberant sound will result in loss of clarity.

All surfaces absorb the same fraction of the sound that reaches them, theoretical reverberation time is proportional to the ratio of value to surface area.

Reverberation time is typically defined as the time required for the sound level to decrease by $60 \mathrm{~dB}$.

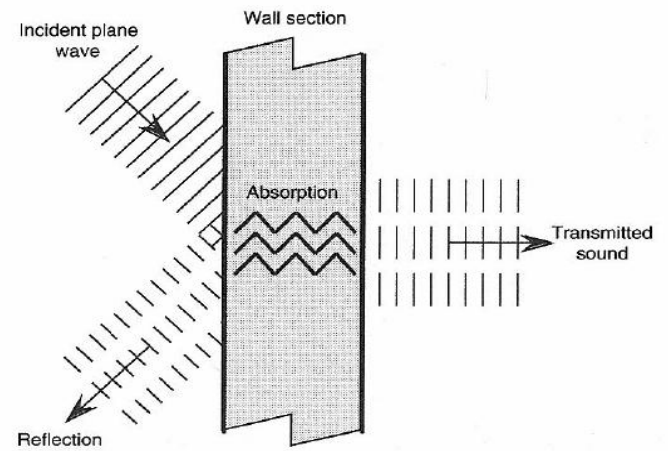

Fig 3: Sound at barrier: reflection, absorption and transmission through boundary.

(Chris Foreman, Jul 6, 2015

\subsection{Confined Sound In An Enclosure S pace}

- Gets sound reflections off of all walls (just like light bouncing off of mirrors ).

- Angle of incidence $=$ Angle of reflection

Law of reflection (light and/or sound) arises from energy/momentum conservation at wall/mirror!)

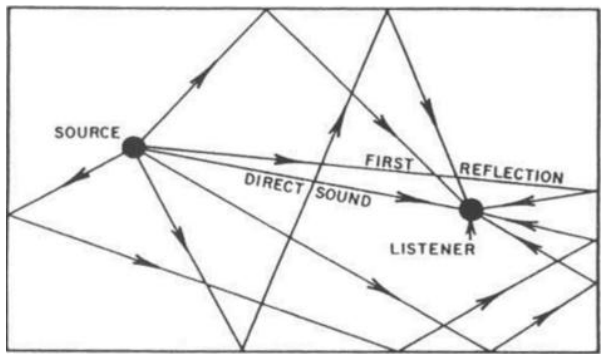

Fig 4: mu ltiple reflection from the walls of a room of a single impulse produce by a sound source. (Steven Errede,2002-2016)

\subsection{Calculating Reverberation Time}

When expressed in units of cubic and square meters, the reverberation time is given by $\mathrm{RT}=0.161 \mathrm{~V} / \mathrm{A}$ Where $\mathrm{V}=$ volu me of the room.

$\mathrm{A}=$ effective total absorption area.

The "total absorption area is calculated as the sum of all surface areas in the room, each multiplied by its respective absorption coefficient. 


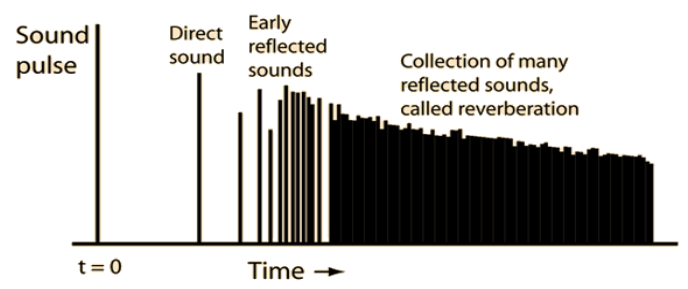

Fig 5: multiple reflection of a sound impulse as heard by a listener.

(Steven Errede,2002-2016)

\subsection{Air Abs or ption}

- Air contributes a substantial amount to the absorption of high frequency sound.

- Taking account of air absorption $\quad \mathrm{RT}=0.161$ $\mathrm{V} /(\mathrm{A}+\mathrm{mV})$

Where $\mathrm{m}$ is constant which varies with air temperature, hu midity, and frequency.

\section{CRITERIA FOR GOOD ACOUSTIC}

- An appropriate reverberation time

- Uniform sound distribution

- An appropriate sound level

- No echo or flutter echo.

Background Noise

An auditorium should meet at least the NC-20 curve and preferably the NC- 15 curve.

\section{GREEK THEATERS}

Theaters were typically based in favor of a hill, with an empty break that slanted down at an edge of roughly 45 degrees. They for the most part had very great acoustics. The decision of place gave a shape to the auditorium that matches consummately the directivity of the human voice, which shows a practically unvarying sound dissemination inside the angle of 180 degrees. There are different developments in Greek theater engineering which create helpful impacts. The skene, worked of wood and later of masonry was arranged under three meters behind the orchestra thus near the entertainers and it went about as both an acoustic reflector for their voices and an acoustic shield for undesirable outer clamor.

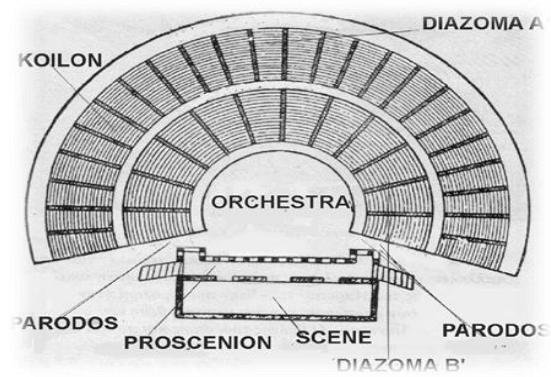

Fig 6: Diagram of the acient Greek theater. (nik v. 2011)

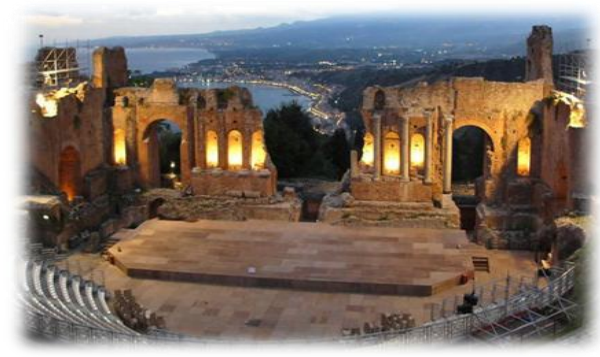

Fig 7: The Greek Theatre by night. (admin on luglio 1st, 2010)

\section{ROMAN THEATERS}

The roman and the late Hellenistic amphitheater took after the earlier Greek seating designs, yet restricted the seating bend to 180 , they included a stage house, a raise acting range, embrace wings and a chorale talked. It was built between AD70 and 81, obliges 40,000 individuals which makes it the biggest seating structure of the antiquated world. the sight lines are incredible from any seat and the dissemination configuration is still utilized as a part of current circumstances. The floor is secured by sand. It's does not require a high level of speech intelligibility by the gathering of people.

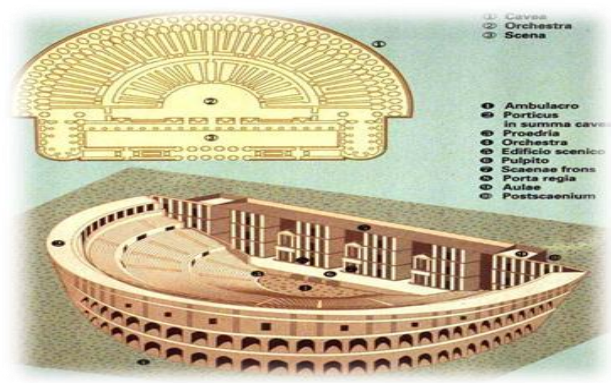

Fig 8: plan and perspective view of roman Theater. (I. castiglione, 2008)

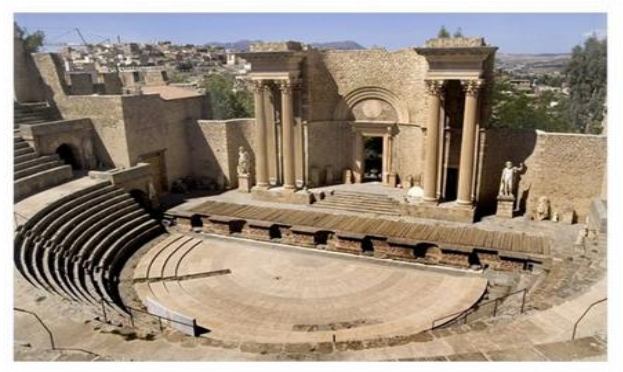

Fig 9: roman theater guelma. ((elaggoune, 2009)

\section{VITRUVIUS POLLIO THEATER}

They said that the area of theaters ought to be on a healthy site with sufficient ventilation (seating ought not confront south, unlimited sightlines were considered especially critical. Furthermore, edge of every row ought to fall on a straight line from the first to the last. 


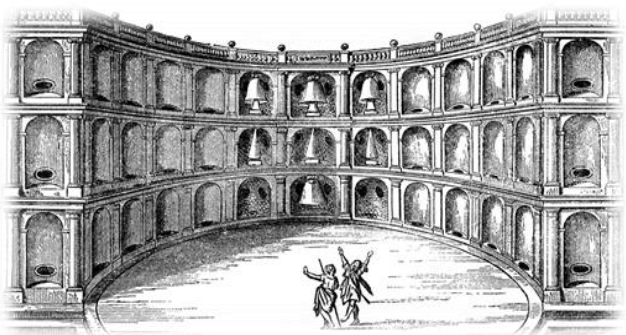

Fig 10: Theater of Vitruvius. (Charles scribner and co., 1871)

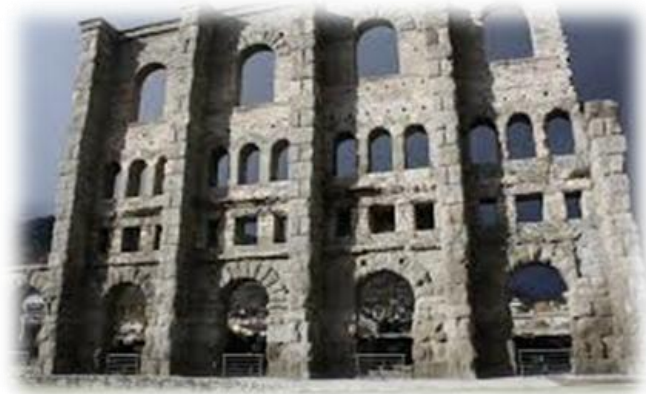

Fig 11: Theater façade, Aosta. (mark cartwright, 2015)

\section{RENAISSANCE THEATERS}

The seating arrangement was semi-curved. It has orchestra and proscenium like roman does. Around the back of the gathering of people there was a colonnade of segments with statues above. They have crafted stage, which fused emerg ing stage floor and sight point viewpoint. The term upstage and down stage develop from this early design practice.

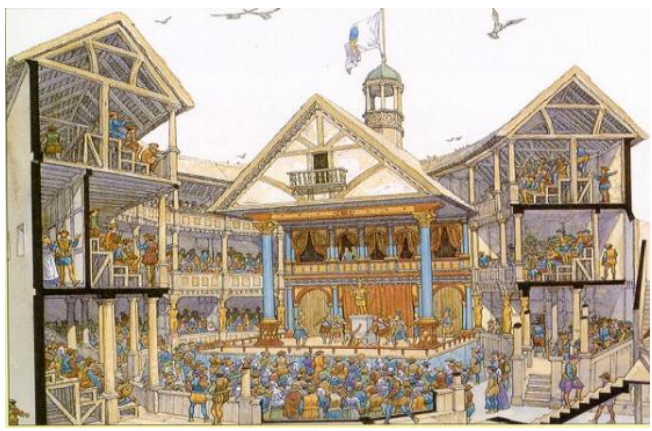

Fig 12: Italian renaissance theater: Teatro farnese. (Giulio Ghirardi, 2014)

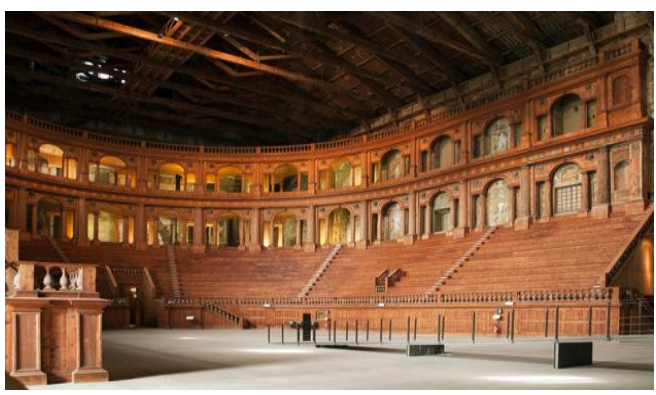

Fig 13: English renaissance theater: Shakespeare. (Giulio Gh irardi, 2014)

\section{BAROQUE THEATER}

The theater farnese in parma, Italy. constructed somewhere around 1618-1628 by Giovanni Battista Aleotti. It has many elements of the modern theaters. It highlighted even set pieces, which required distending side dividers on either side of the stage. It permitted set changes to be made and gave entrance spaces as an afterthought wing for the on-screen characters to utilize. The U-shape seating arrangement of action managed the supporters a view, of the stage, as well as of the sovereign, whose container was situated on the middle line.

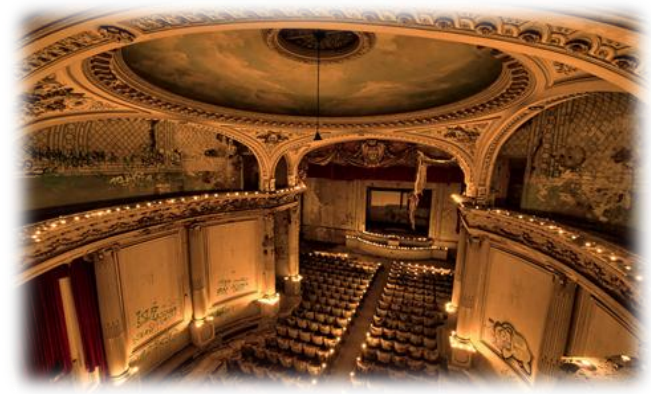

Fig 14: Theater baroque, France. (Nikon Morris 2014)

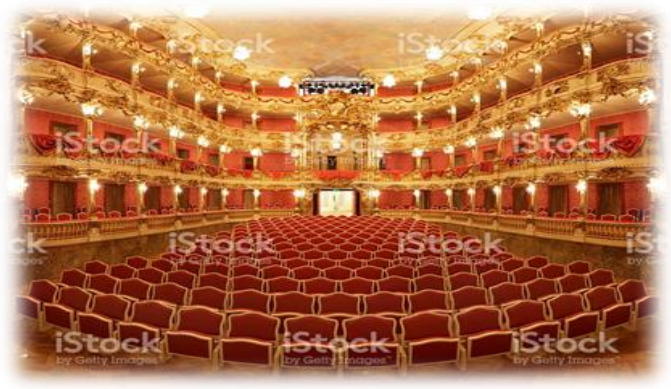

Fig 15: baroque theater view into the audience. (Stories \& Trends Partners, 2012)

\section{CASE STUDY: EPIDAURUS THEATRE}

Peloponnese: The Ancient Theater of Epidaurus is viewed as the best protected antiquated theater in Greece as far as its ideal acoustics and fine structure. It was developed in the late 4th century $\mathrm{BC}$ and it was settled in two phases. design by Polykleitos in west side of Cynortion mountain, Greece.

The theater is wondered for its extraordinary acoustics. Any sound on the open air stage, whether a stentorian voice or a whisper, a full breath or the sound of a match struck is splendidly discernable to all onlookers, even in the highest row of seats, that is, almost $60 \mathrm{~m}$ away. The response to what makes the sound transmit so well orig inates from late logical reviews: The course of action of the ventured seating rows goes about as an acoustic channel that stifles low-frequency background 
sounds, for example, the mumbles of the group of onlookers, while intensifying the high-frequency sounds from the stage.

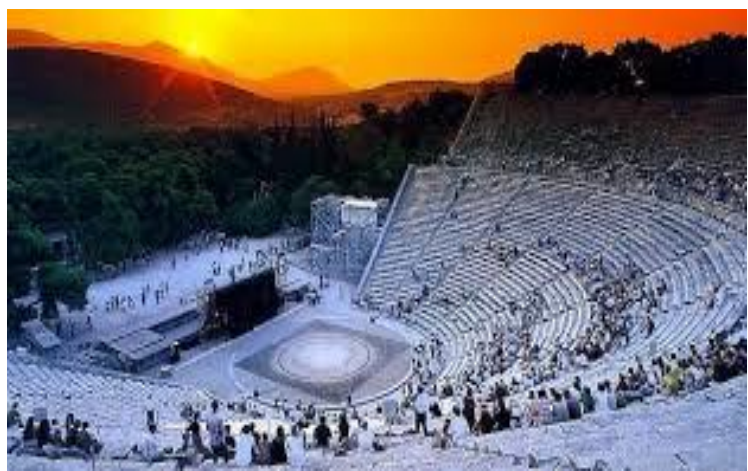

Fig 16: The ancient theater of Epidauvrus. (Martina Di Fresco, 2015)

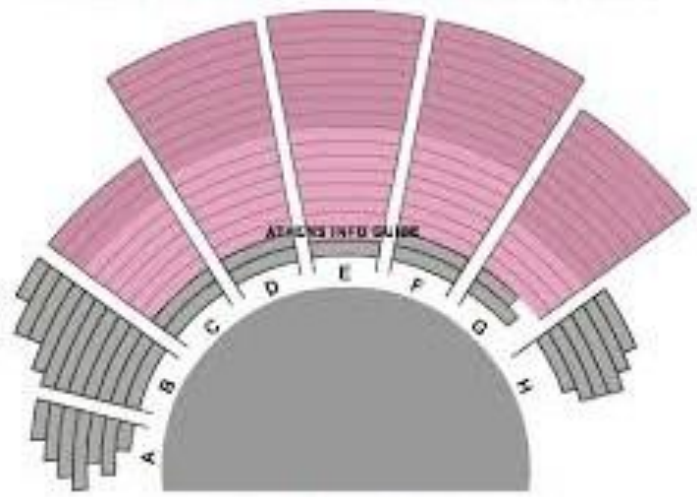

Fig 17: seating plan of the Epidauvrus theater. (Athens Info Guide, 2004-2009)

\subsection{Acoustics of The Epidaurus Theatre}

The flawlessness of the geometrical arrangement of seats, results in numerous early reflected sounds being gotten by all audience members in the auditorium together with the direct sound. The lower part of the auditorium hover stretches out to 210 degrees and the upper part to 192 degrees. The focal areas of seats have their concentration at the focal point of the orchestra. Be that as it may, the augmentations of the emanating passageways of the two wedges of seats, at either side underneath the diazoma, have their central focuses situated at either side of the focal point of the orchestra. This seating format with three foci has the imperative acoustical impact in that there is a considerably less maintained resound tone close to the focal point of the orchestra than in theaters were the rows of seats are situated on flawless circles with just a single regular focus at the center of the orchestra. In cross section, the layered seating is slanted at a continually expanding edge as it retreats from the orchestra towards the back of the auditorium. A fanciful straight line moved from back to front disregards the concave curve of the seating underneath. On plan, the levels of seats are additionally bended giving the auditorium the type of a shell. The gathering of people is held together in this shell, or bowl like frame, as close as could reasonably be expected to the orchestra. This frame holds sound, minimizes the sound vitality misfortune amid sound generation and encourages reverberation. It's additionally guarantees that observers' lines of view are unhindered by the row of individuals before them. The flawlessness of the geometrical course of action results in the acoustical and visual brilliance. Both visual and acoustic criteria overwhelm the outline of the theater. Reflected sounds achieve the audience inside 50 milliseconds after the underlying sound, and a consonance marvel is produced. It delivers in the audience's cognizance a solitary acoustical picture of more prominent power and upgraded quality than that of the direct sound alone.

To ensure a high-quality product, diagrams and lettering MUST be either computer-drafted or drawn using India in $\mathrm{k}$.

- Discovered under a layer of earth and uncovered in 1881

- Dates back to fourth century B.C

- A group of onlookers of 15000 can hear performers and on-screen characters unintensified - even from the back line $(60 \mathrm{~m}$ away)

- The acoustic properties have been somewhat of a secret for some time however were as of late settled by some folks at Georgia Institute of Technology

\subsection{How does it work?}

The theater, because of its shape, is an amplifier. The fascinating thing is that it just amplifies certain frequencies which happen to be only the correct ones - it's not by any means known whether this was purposeful.

9.3 It's the steps - they frame a productive acoustic filter which minimizes background noise and amp lifier the performing actors and artists.

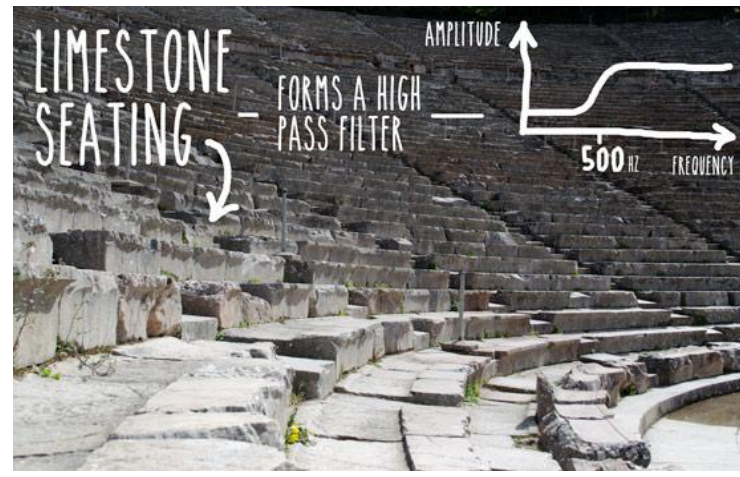

Fig 18: materials used for the seating at Epidauvrus (Martina Di Fresco, 2015) 


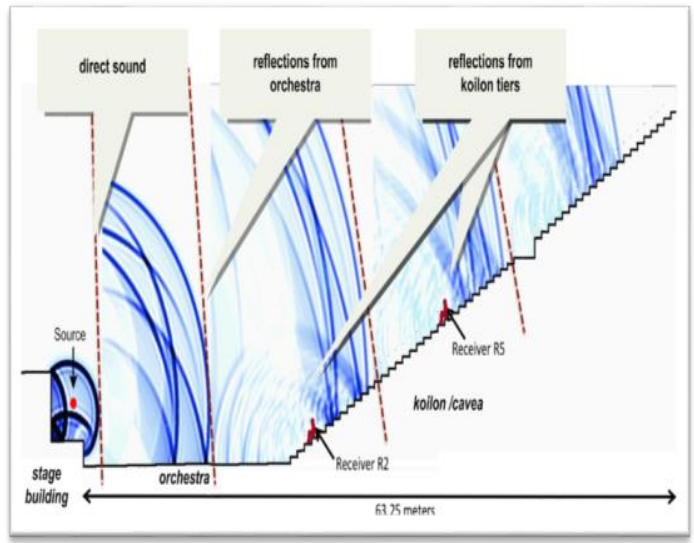

Fig 19: Acoustic wave engendering 2D model for the Epidaurus theater. The blue curves demonstrate the direct and reflected waves at progressive time occurrences showed by the red spotted lines. Alongside the forward proliferating wave fronts, backscattered and reflected waves from the seating lines are delivered. (T. Lokki, 2013)

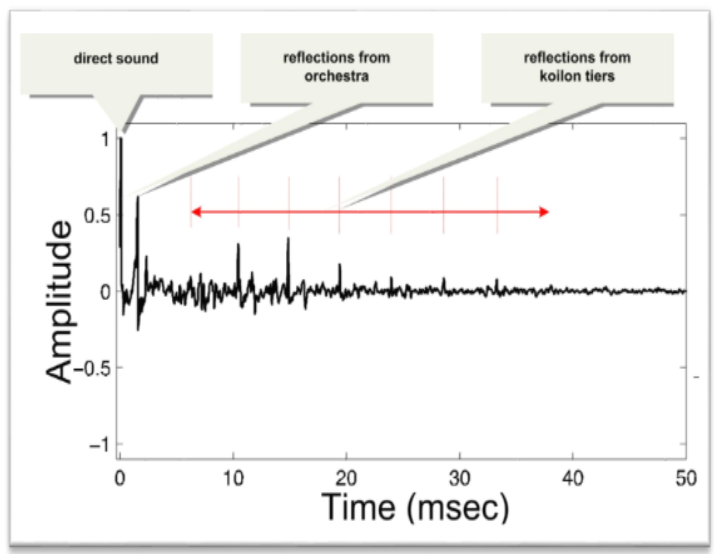

Fig 20: Acoustic reaction estimation for the Epidaurus theater, accepting that the source emanates a short heartbeat and the mouthpiece is at a seat at 15 meters. Given that today the stage building does not exist, the principal reflection arrives instantly from the orchestra ground. Seven progressive and intermittent reflections can be seen from the top and the risers of adjoining seat lines. Their vitality is diminished inside approx. 40 milliseconds after the landing of the immediate sound (S. Vassilantonopoulos, 2004).

\section{THE TWENTIETH CENTURY THEATERS}

Architectural acoustics came to perceived as a science and a crafts manship, the comprehension of a large portion of the standards of acoustical design did not in all cases prompt to changes in auditorium. The more normal part of room acoustic including clamor and vibration control and advancement of viable acoustical materials, experienced market enhancements.
Preceding sabine's work toward the start of the $20^{\text {th }}$ century, there was little to go on. Jean louis Charles Garnier (1825-1898), designer of the Paris musical drama house, communicated his dissatisfaction at the time.

"I gave myself pains to master this bizarre science (of acoustics) but... now here did I find a rule to guide me: on the contrary, nothing but contradictory statements...I must explain that I have adopted no principle, that my plan has been based on no theory, and that I leave success or failure to chance alone...like an acrobat who closes his eyes and clings to the ropes of an ascending balloon". (Garnier 1880).

Since Sabine's commitments in the early 1900 's, there has been a century of specialized advances. Concentrates supported by the EPA and HUD in the 1970's were especially beneficial. Works in Canada, Europe, and Japan has likewise contributed incredibly to the progression of the field.

\section{CASE STUDY: THE WALT DISNEY CONCERT (AN ACOUSTICAL WONDER)}

Design by Frank Gehry between 1999-2003 in south grand avenue in downtown of Los Angeles. The acoustician of the building was Yusuhisa Toyota.

Design as one vast volume, the auditorium permits the inhabitants to be in an indistinguishable space from the orchestra. This takes into account a feeling of closeness inside the hall. Composed as a "shoe box outline" with vertical "vineyard" seating at the edges of the orchestra.

A 1:10 scale model was built with a specific end goal to test and study the acoustics of the auditorium. The frequency of the sounds utilized for testing were expanded as a part of request to lessen the wavelengths by a component of ten. To oust the oxygen and water vapor that retain highfrequency sound the model was loaded with nitrogen. An acoustical expert, Yasuhisa Toyota, sharpened the hall's sound.

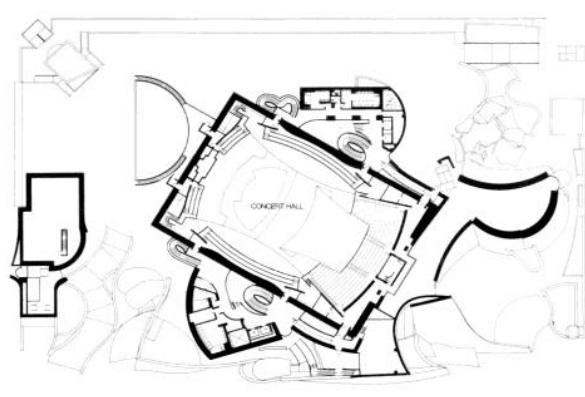

Fig 21: Gallery level plan.

(http://www.archdaily.com/441358/ad-c lassics -waltdisney-concert-hall-frank-gehry). 


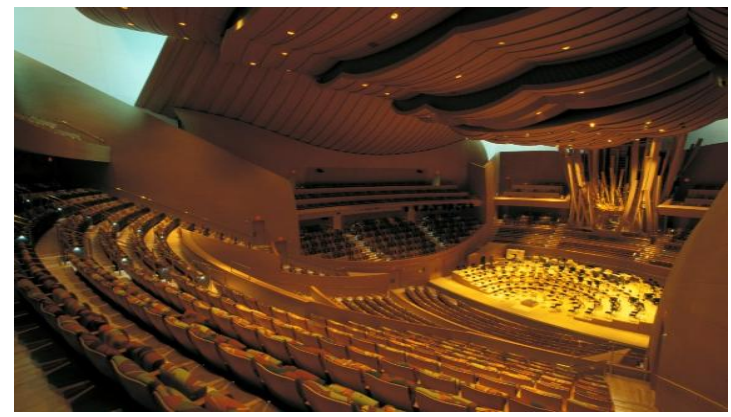

Fig 22: wdch. Built interior.

((http://www.archdaily.co m/441358/ad-classicswalt-d isney-concert-hall-frank-gehry)

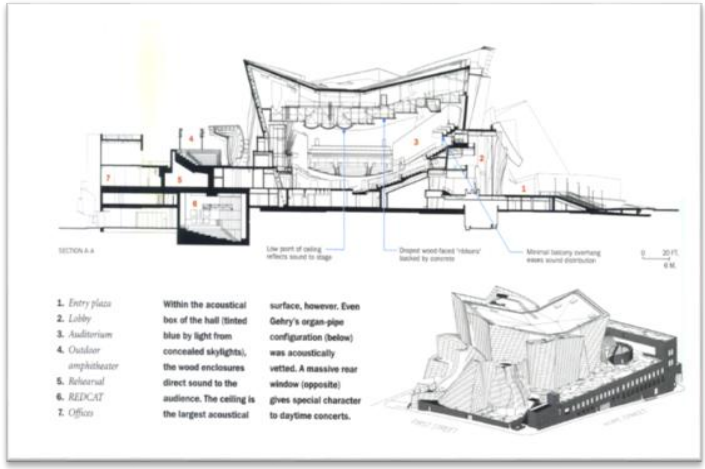

Fig 23: acoustical bo x of the hall.

(http://www.slideshare.net/ Dan Johnson, 2016)

\subsection{ACOUS TICAL SOLUTIONS}

- The curved billowing ceiling and partitions become part of the acoustical system.

- One of the difficulties Toyota confronted was accomplishing full sound coverage from an unamplified orchestra that had no volume control. The vineyard configuration calls for terraced seating to encompass the orchestra taking into account all the more level surfaces. Which would expand the range for sound to be reflected-an essential component for the achievement of an unamplified orchestra.

- Employed concave shapes wherever conceivable. Indeed, the "walls" encompassing the Disney Hall are an optical fantasy. They are made of transparent mesh to allow sound to effectively go through and reflect off whatever lies behind (row upon row of hidden concaves). The result of Toyota' design is a sound depicted as "acoustical clarity and warmth".

- Made from Alaskan yellow cedar, the stages gives reverberation and can be arranged to hold bigger performance by expelling the first rows in Orchestra. An organ's wooden pipes are frequently inconspicuous, yet these are up front to associate it with the wood inside of the hall. The pipes are likewise bended and twisted, which had not been done before and would they be able to can be moved around and connected to four unique areas on the stage.

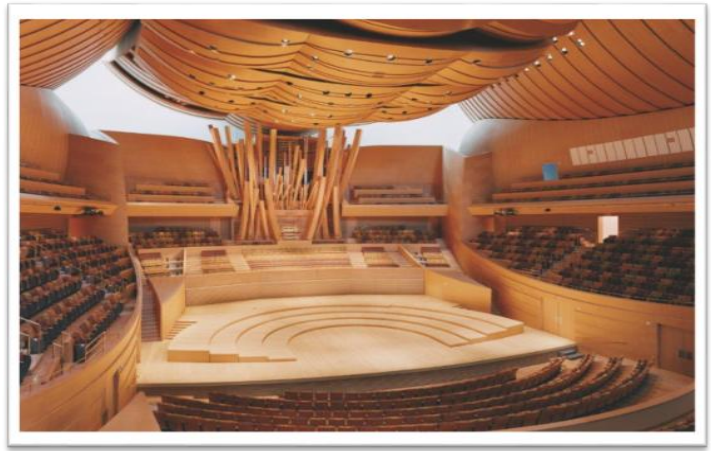

Fig 24: Los Angeles Philharmonic Association. (http://www .archdaily.com/441358/ad-c las sics-waltdisney-concert-hall-fran k-gehry)

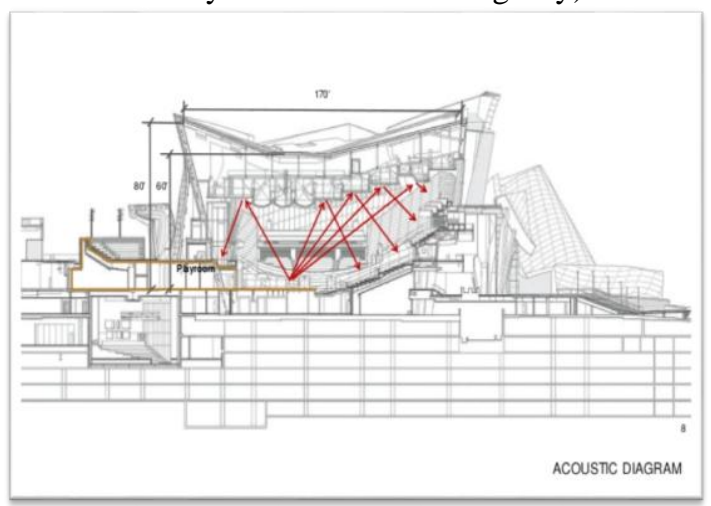

Fig 25: Acoustic Diagram.

(http://www.slideshare.net/ Dan Johnson, 2016)

\section{ADVANTAGES OF ACOUSTICS}

Acoustics can be a convoluted and misjudged part of custom integration, however there are significant advantages of taking care getting it correct. An acoustics has accumulated an undeserved notoriety as some sort of dark art. In truth, acoustics is a profoundly logical process that can be as basic or as complex as you want to make it. Past all the terrible buildup lie some convincing explanations behind each custom integrator to get required in acoustics are:

- Acoustics enhances the frequency reaction in the space

- Acoustics enhances the time reaction in the space

- Acoustics enhances the sound field integration in the space

- Acoustics enhances coherence in the space

- Acoustics enhances intelligibility in the space

- Acoustics keeps great sound in and terrible sound out

- Acoustics increases a room's comfort factor.

\section{LOUDSPEAKER SYSTEM PROB LEMS}

What causes poor quality sound? There are a couple of normal components that influence how a 
loudspeaker performs in an auditorium context. In many cases, it is expected somewhat to the challenging acoustic qualities of an auditorium and halfway because of the execution attributes and wasteful as pects of the loudspeaker. Concrete floors and walls are horrendous for sound quality. Or, you might have an oddly shaped hall. Frequency distortions from loudspeaker add to sloppy or unintelligible speech of varying quality across a venue. Older established auditoriums were not acoustically design to handle today's sound requirements. These issues associate with each other and add to poor sound quality and intelligibility misfortune.

Solution: Flat-panel innovation is so new you might not have known about it yet. It is the consequence of the previous 20 years of innovative work to tackle these normal audio problems: a flat speaker about a quarter-inch thick and the extent of a publication. There are various advantages that conquer the physical impediments of cone speakers and their resultant quality issues. And the use of lime-stone material instead of using concrete for floors and wall.

\section{DICUSSIONS AND FINDINGS}

Key issues for Architects, acousticians, Engineers and other stakeholders etc. to consider when dealing with the design of auditorium acoustics.

The auditorium is a focal and essential space utilized for various sorts of performance like lectures, award ceremonies, dramatic plays, musical theatre productions, concert performances of orchestra, band, chorus, jazz band, battles of the bands, dance competitions etc. These differed occasions put a scope of requests on the space. For all occasions, it is basic that everybody in the space hear, plainly and charmingly, everything that is presented. This was the objective of acoustical design for auditoriu m spaces.

From the first case study, the Epidaurus theatre (past auditorium). The corrugation on the surface of the seats go about as natural acoustic traps. In spite of the fact that this impact would appear to likewise expel the low frequencies from the performing artists' voices, audience members actually fill in the missing bit of the sound range through a phenomenon known as virtual pitch. The human cerebrum reproduces the missing frequencies, creating the virtual pitch phenomenon, as in listening to somebody talking on a phone with no low end. Incredibly, the Greek manufacturers of the theater did not themselves comprehend the rule that prompted to the extraordinary audibility of sound from the stage.

From the second case study, the Walt Disney concert hall (present auditorium). An orchestra is just tantamount to the hall they play in, and to that degree, a hall turns into an instrument of its orchestra. Acoustic tests were performed on a 1:10 scale model. Everything must be decreased by a similar amount, which required that the frequency of sounds be expanded ten times to diminish the wavelength to a tenth of normal, and the model was loaded with nitrogen to oust the oxygen and water vapor that absorb high-frequency sounds. Testing was viewed as hazardous since nobody could take in the oxygen-inadequate model. The acoustical clarity of the hall brought about individuals from the Los Angeles Philharmonic to be both energized and on edge. Collection that they had learned, and knew how to play well, would need to be relearned in the new Hall.

From all the case studies, both the past and the present auditorium in times of method, technics and materials shear some common characteristics and features, and at the same time have some differences.

From all the case studies, both periods (past and present auditorium) shear some common similarities in terms characteristics and features, and at the same time have differences in methods, technics and materials been use in achieving excellent acoustics of the auditoriums (theatres).

These similarities include the consideration of the shape of the space, seating arrangement and the slop of the it and the stage with orchestra. While the differences between the periods was manly the use of materials like the past theatres use lime-stone of the seating and stairs which forms a high efficient acoustic filter and minimizes background noise and amplifies the actors and musicians. And the present auditorium (theatres) use sound isolation materials on door, windows, walls, ceilings and floors.

Although the present of and past acoustical solutions for auditoriums where somehow intergraded base on the methods, technics and materials, and they both have excellent acoustics, if line-stone would be used in modern way as material, it will improve the acoustics quality of the present auditoriums which will reduce the problem of loudspeaker system (in adequate loud speaker coverage). By the introduction of it, there will be many positive effects on the acoustics quality of the present auditoriums acoustics.

Acoustics are very important in spaces most especially in auditoriums (theaters). Some of this major benefits includes: making the client happy, it improves the frequency response in the space, improves sound field integration in the space, improves time response in the space, improves intelligibility in the space, it also keeps good sound in and bad sound out which also increases comfort factor and gives you a competitive edge. 


\section{CONCLUSION}

Architectural acoustics has been depicted as something of a dark art or maybe more beneficently, an arcane science. While not absolutely an art, getting it done it brings about structures that are wonderful and additionally utilitarian. To deliver workmanship, be that as it may, the specialist should first ace the investigation of the specialty before valuable innovativeness is conceivable. just as porter must learn dirt or painter his oils.

The rather hit-and-miss days of concert hall design preceding the early 1980 s are presently a relic of past times for competent consultants. The critical characteristics for good acoustics from the past to present are currently much better comprehended, the ability to test design before construction now exist and the status of the acoustician in respect to the architect is greatly upgraded. Hence, there is presently much more noteworthy trust in auditorium acoustic design, with a sensible desire of good acoustics in auditoriums. In recent years, the cost of achievement has been more preservationist plan with more noteworthy dependence on points of reference. nevertheless, the research goes on more stays to be found in the pursuit for how "superb" acoustics solution where accomplish.

The acoustic nature of these ancient theaters (Epidaurus) stuns guests and specialists alike. As of late, the across the board utilization of acoustic reproduction programming and of complex PC models has permitted a superior comprehension of the extraordinary open amphitheater acoustics, notwithstanding when the theaters are known exclusively from archeological records. As an experiment, the classical/Hellenistic theater of Epidaurus in southern Greece is frequently examined which is renowned for its close flawless speech intelligibility.

The sound of a concert hall characterizes what will isolate a notorious one to a customary one yet it appears that the Walt Disney Concert Hall acoustics was perfected through the hands of Yasuhis a Toyota who made the one of a kind design mix in well with the acoustic solutions, A 1:10 scale model was built keeping in mind the end goal to test and study the acoustics of the auditorium.

According to this research, its evadable that auditorium acoustics of both the past and present have excellent acoustics solutions. But still the present auditoriums have the problem of poor quality sound cause by loudspeaker problems. The solution is to use flat panel technology and limestone material instead of using concrete floors and walls that are horrible for sound quality it will also substantially reduce the reverberation noise.

\section{REFERENCES}

Journal Papers:

[1]. Toyota, Yasuhisa. "Acoustical Design of The Walt Disney Concert Hall In Los Angeles". The Journal of the Acoustical Society of America 105.2 (1999): 987. Web.

[2]. M Ozaki, Y. Adachi, Y. Iwahori, and N. Ishii, Application of fuzzy theory to writer recognition of Chinese characters, International Journal of Modelling and Simulation, 18(2), 1998, 112-116.

[3]. "Auditorium Acoustics And Architectural Design". Choice Reviews Online 31.02 (1993): 31-0705-31-0705. Web.

[4]. Banavalkar, P. V. "Walt Disney Concert Hall, Los Angeles, California". Structural Engineering International 5.1 (1995): 2830. Web.

[5]. Barron, Mike. "The Search For Excellence In Auditorium Acoustics". Acoustics Australia 43.1 (2015): 25-31. Web.

[6]. Bradley, J. S. "Ten Years Of Newer Auditorium Acoustics Measurements". The Journal of the Acoustical Society of America 89.4B (1991): 1856. Web.

[7]. Elkhateeb, Ahmed Ali. "The Acoustical Design Of The New Lecture Auditorium, Faculty Of Law, Ain Shams University". Ain Shams Engineering Journal 3.3 (2012): 219-235. Web.

[8]. French, Gil. "Los Angeles: The Walt Disney Concert Hall And New Music". Teтро 58.229 (2004): 78-79. Web.

[9]. Lord, P. "Auditorium Acoustics". Building and Environment 11.3 (1976): 215. Web.

Books:

[10]. Long, Marshall. Architectural Acoustics. 1st ed. Amsterdam: Elsevier/Academic Press, 2006. Print.

[11]. Brooks, Christopher N. Architectural Acoustics. 1st ed. Jefferson, N.C.: McFarland \& Co., 2003. Print.

\section{Website:}

[12]. "AD Classics: Walt Disney Concert Hall / Frank Gehry". ArchDaily. N.p., 2016. Web. 13 Dec. 2016.

[13]. "» The Origins Of Building Acoustics For Theatre And Music Performances - John Mourjopoulos". Acoustics.org. N.p., 2016. Web. 13 Dec. 2016.

[14]. "Auditorium Acoustics". Slideshare.net. N.p., 2016. Web. 13 Dec. 2016. 